\title{
Is Climate Change Contributing to Food Insecurity and Poor Health Outcomes in Mozambique?
}

\author{
Macassa G'*, Militao $\mathrm{E}^{2}$ and Francisco J DC ${ }^{3}$ \\ ${ }^{1}$ Department of Public Health and Sports Sciences, \\ University of Gavle, Sweden \\ ${ }^{2}$ Department of Chemistry, Eduardo Mondlane \\ University, Mozambique \\ ${ }^{3}$ Department of Chemical Engineering, Eduardo \\ Mondlane University, Mozambique
}

*Corresponding author: Gloria Macassa, Department of Public Health and Sports Sciences, University of Gavle, 80176 Gavle, Sweden

Received: November 24, 2020; Accepted: J anuary 12, 2021; Published: J anuary 19, 2021

\begin{abstract}
Climate change poses a considerable threat to food security, with potentially existential economic, political and social outcomes for the entire humanity. The impact will be especially severe in low and middle-income countries that are struggling to meet the needs of a growing population. This mini-review aims to contribute to the global and, specifically, the Mozambican debate on the potential impact of climate change on food security and how it might affect the health of current and future generations. In Mozambique, climate change has already had an impact on food security and in some instances, it is exacerbating already existing diseases such as diarrhoea, malaria and cholera. However, more research is needed using empirical data that will shed light on the potential pathways and mechanisms of climate change, and its relationship with food insecurity and health outcomes. Furthermore, to ensure that climate change does not worsen the prevalence of food insecurity that is currently ravaging the country, Mozambique needs to implement all the adaptation and mitigation strategies, which have already been approved and adopted in the national climate change plan.
\end{abstract}

Keywords: Mozambique; Climate change; Food insecurity; Health outcomes

\section{Introduction}

There is now global recognition that climate change poses a considerable threat to global food security, with potentially existential economic, political, and social outcomes for the entire humanity [1-4]. This is because climate change threatens a very complex global food system, which is already struggling to meet the needs of a growing and changing population. Climate change is likely to contribute to food insecurity across the world, but especially in low and middle-income countries $[5,6]$. It is suggested that changing weather patterns such as increasing temperatures, increased rainfall and extreme weather events are likely to further exacerbate food insecurity as crops are damaged and destroyed. This will affect the production and distribution of food, which will result in reduced access and availability and, consequently, increased costs $[5,6]$. Furthermore, the reduction in access to affordable and nutritious food may result in diet-related health outcomes such as malnutrition, as well increased risk of chronic diseases [7]. It is argued that climate change will be highly differentiated across continents, countries and livelihood systems, according to local resource endowments, the nature of agriculture (mechanized versus traditional, hand toolbased; irrigated versus rain-fed; commercial versus subsistenceoriented), urbanization and economic diversification (agriculture versus industrial and service sectors) and many other environmental and socio-economic variables $[8,9]$. As a consequence, climate change is also expected to contribute to internal and international migration $[10,11]$. Regarding developing countries, there is good evidence that climate change will compound existing food insecurity and undernutrition [12-15]. For instance, some have predicted regarding the tropics and subtropics, that by the end of this century, the average summer temperature will exceed the hottest summer temperature on record, with potentially serious consequences for food production that could affect the $50 \%$ of the world's population living in these regions [16,17]. For instance, a study carried out in the Peruvian Andes found that maize production declined by $21-29 \%$ in response to new soil conditions directly related to new climatic conditions [6]. Furthermore, the production of maize and potatoes declined by $87 \%$ when plants were grown under warmer temperatures, mainly as a result of the greater incidence of novel pests. The same study found that crop quality and value also declined under simulated migration and warming scenarios [6]. This mini-review attempts to contribute to the global conversation on the potential impact of climate change on food security and how it might affect the health of current and future generations. First, we address the relationship between climate change, food insecurity and health in Mozambique. Thereafter, we briefly discuss how climate change might already be affecting the health and wellbeing of different societal groups, as well as which adaptation measures can help curb the potential devastation that climate change might bring to the health of the poorest segments of the population.

\section{Climate Change, Food Insecurity and Health}

"Food security" is defined as the condition that exists when all people, at all times, have physical and economic access to sufficient, safe and nutritious food to meet their dietary needs and food preferences for an active and healthy life [15]. A given population is food secure if it has enough nutritious food that is affordable and if it is sufficiently protected against future disruptions to the access to adequate food. Food security has four dimensions: availability (which refers to the amount, type and quality of food a unit, such as a community, household, or individual, has at its disposal to 
consume), accessibility (the ability of a unit to obtain access to the type, quality and quantity of food it requires), utilization (the capacity of an individual or household to consume and benefit from food) and stability (the requirement that food-secure people have access to appropriate food at all times) [18,19]. In addition, food security has been found to be associated with socio-economic factors such as wealth, age, gender, and status within the household. Climate change will probably affect all four key dimensions of food supply: availability, accessibility, utilization and stability. For instance, in a review of the impact of climate change and food security in sub-Saharan Africa, Zewdie found that temperature, precipitation, $\mathrm{CO}_{2}$ concentration and extreme climate events affect all components of food security [5]. The most direct impact concerned food availability through reduced net crop production. Furthermore, the author found that there was also an impact on food accessibility and utilization although these were not as well researched as availability [5]. The pathways through which climate change impacts food security (and its dimensions) to influence human health outcomes are complex [5,19]. It is argued that climate-related disruptions in the food system can indirectly impact health through diminishing food security, which is a key determinant of health. In addition, human health may also be directly affected by the physical effects of climate change on the food system, primarily through food safety and nutrition [19]. Diet plays an important role in premature death from many chronic diseases. This can occur via undernutrition (increased susceptibility and reduced resilience to chronic diseases, as well as cognitive dysfunction) and overconsumption (which, together with reduction of physical activity, is a leading cause of obesity, Cardiovascular Disease (CVD), diabetes type II and some types of cancer) [20,21]. For instance, drought and long-term drying conditions, higher temperatures, rising sea levels, increasing frequency of flooding and acidification of oceans contribute to impaired yield, quality and affordability of food $[20,21]$. Furthermore, climate-induced disturbances to traditional living, hunting and eating patterns among rural and remote populations may affect food security through reduced options for physical mobility and increased reliance on imported energy-dense, processed foods, thus potentially inducing obesity, CVD and diabetes [21-23].

\section{Climate Change, Food Insecurity and Health in Mozambique}

According to national and international reports, Mozambique is highly vulnerable to climate change, ranking eleventh among the most vulnerable countries in the world and ninth in Africa [24]. The country's high vulnerability is attributable to its long coastline, with large areas lying below sea level; its location in the intertropical convergence zone, downstream from nine shared river basins; and a sharp drop in altitude from the interior to the coast, resulting in a high level of runoff that causes short-term floods when there is greater than average rainfall in the shared international watersheds. Moreover, the country has a weak infrastructure of roads, water retention and conservation dams, and grain storage silos; and a weak purchasing power, with inputs by small farmers who practise agriculture irrigated by rain. There is little investment in advanced technologies. The country has a fragile social infrastructure and few services, with main emphasis on health and sanitation. The levels of poverty and illiteracy are high. Furthermore, it is argued that Mozambique's vulnerability is compounded by its high susceptibility to natural disasters associated with a lack of coping and adaptive capacity [24]. In the country, climate change has manifested itself mainly in the form of extreme weather events such as drought, floods and tropical cyclones. Drought has affected mostly districts in the provinces of Maputo, Gaza and Sofala, while floods have affected Maputo, Gaza, Inhambane, Manica, Tete, Zambézia, and Cabo Delgado Provinces. Regarding tropical cyclones, these are more frequent in the coastal areas of the provinces of Inhambane, Sofala and Zambezia [24]. As elsewhere, climate change will exacerbate the risk of hunger and undernutrition in the country. Under climate change, the frequency and intensity of weather disasters such as droughts, floods and storms could increase, with an adverse impact on livelihoods and food security [25]. Also, climate-related disasters have the potential to destroy crops, critical infrastructure, and key community assets, thus deteriorating livelihoods and exacerbating poverty. In addition the sea level will rise as a result of climate change, affecting livelihoods in the coastal areas and river deltas. Accelerated glacial melt will also affect the quantity and reliability of water available globally. Under warming trends, glacial melt could accelerate, and the melt season would begin earlier in the year.

In addition, across Mozambique, climate change could affect all dimensions of food security and nutrition in complex ways through impacting food production [25]. As mentioned above, climate change will affect the production of some staple crops, and future climate change threatens to exacerbate this. In addition, high temperatures will have an impact on yields, while changes in rainfall could affect both crop quality and quantity. Also, climate change will affect food access through increased prices which in turn can impact physical and mental health $[25,26]$. In Mozambique, for the most vulnerable people, reduced agricultural output will also mean that many families will have a lower income, which, as discussed above, is known to be associated with poor health outcomes. This would create further stresses to the poorest people as they will be forced to sacrifice a larger portion of their income to meet their nutritional requirements. Furthermore, in terms of food utilization, climate-related risks are likely to affect calorie intake, particularly in areas of the country where chronic food insecurity is already a significant problem. Changing climatic conditions could also create a vicious cycle of disease (physical and psychological) and hunger. Climate change will therefore affect the nutritional status of large segments of the Mozambican population through impacts on food security, dietary diversity, and care practices that will affect health and wellbeing [27].

\section{Discussion}

Mozambique is not a large producer of Greenhouse Gases (GHGs) and is therefore not a major contributor to climate change. The country actively supports international initiatives regarding mitigation and adaptation measures to curb climate change. However, although there is evidence of climate change impact on food security in Mozambique, no studies have attempted to investigate how this is affecting population health. There is evidence that climate change will impact almost all components of food security (availability, accessibility, utilization and stability) [25]. Of great importance for population health in Mozambique and other low-income countries is that climate change will exacerbate the already existing inequalities in overall mortality but specifically child mortality [28]. Furthermore, climate-related risks might undo the few gains made by the country 
in terms of poverty reduction and literacy, especially among the most vulnerable groups, the very poor, often women [29,30]. It is suggested that the effects of climate change are already being felt in the country, especially as a result of frequent extreme weather events such as heat and cold waves, flooding and drought [27]. Agriculture is the backbone and a priority sector of the Mozambican economy. Agriculture plays an important role in food and nutrition security, not only as a source of food and of diversification of food, but also as a source of employment, providing income for the rural population [31]. In 2014, the Mozambican Secretariado Tecnico de Seguranca Alimentar e Nutricional (Technical Secretariat for Food Security and Nutrition (SETSAN)) estimated that about $24 \%$ of households nationwide suffered chronic malnutrition and chronic food insecurity, and an estimated $3.5 \%$ of households were suffering acute food insecurity. Chronic food insecurity is more prevalent in the northern provinces and less in the southern provinces and the country's capital Maputo [31]. Furthermore, food insecurity was reported to be greatest in rural areas. By 2017, the country had an estimated seven million people who were food insecure and of those, six million were in a state of chronic food insecurity [32]. According to a report by the United States Agency for International Development (USAID), climatic change is exacerbating the occurrence of malaria and diarrhoeal diseases which are still main killers, especially in children under the age of 5 [33]. Moreover, a more recent report states that the level of moderate to severe growth delay among children was around $40 \%$ across the country and that malnutrition had increased to very serious levels in central and northern Mozambique [34]. The same report pointed out that almost $43 \%$ of children experienced delayed development associated with nutritional deficiencies. Furthermore, the report indicated that, for the first time in years, the country was reporting cases of pellagra - a disease linked to vitamin B3 deficiency, which results from limited food diversity [34]. In Mozambique, increased temperatures, droughts and floods are already having impact on the health of the population. For instance, the rising temperatures and frequent flooding due to a rise in heavy rainfall events have resulted in increasing malaria cases due to increased mosquito breeding and rate of mosquito development [33]. Furthermore, climate change variability is associated with increasing cholera outbreaks, especially because increased and intense precipitation events are likely to cause flooding of poorly located latrines, which will in all probability also increase the prevalence of other enteric diseases. Also, climate change is likely to exacerbate poverty through reduction of income, with especially severe consequences for those whose resources are already stretched, such as families of HIV/AIDS sufferers. Also, and most importantly, climate change can further widen inequalities in health, especially those that are deemed unfair and unjust and can have consequences for physical and psychological health [33,34]. In 2019, CARE International estimated that almost 1.6 million people in southern and central Mozambique were at the time in need of assistance as a consequence of climate change effects. These effects occurred in the form of drought and severe weather events [35]. In addition, it was pointed out that there were severe food shortages, particularly among children under the age of 5 , some of whom were experiencing acute malnutrition. At the time, CARE International reported that crops were failing, and that communities did not have enough to eat and could not produce enough to sell, which also triggered high risk-behaviours and negative coping mechanisms [35].

\section{Mozambique climate adaptation plan and implications for food security and health}

In 2012, the Mozambican government approved and adopted the National Climate Change Adaptation and Mitigation Strategy (NCCAMS) plan covering the period 2013-2025. The NCCAMS's general objective is to "establish the action guidelines to create resilience through climate risk reduction in communities and the national economy, and [through] promoting low-carbon development and the green economy through its integration in the sectoral and local planning process" [36]. The specific objectives of the NCCAMS are: (a) for Mozambique to become resilient to the impacts of climate change, reducing climate risks to people and property to a minimum, and restoring and ensuring the rational use and protection of natural and physical capital; (b) to identify and make use of opportunities to reduce GHG emissions that simultaneously contribute to the sustainable use of natural resources and access to financial and technological resources at affordable prices, and reduce pollution and environmental degradation, promoting low-carbon development; and (c) to build institutional and human capacity, as well as explore opportunities to access technological and financial resources, for the implementation of the NCCAMS [36]. Furthermore, the strategic plan defines adaptation and climate risk reduction as a national priority, while recognizing the need to make use of the opportunities and resources that the country has, without compromising development to current and future generations [36].

Despite this positive development, a study that analysed everyday realities of climate change adaptation found that the international discourse around the impact, in Mozambique, of climate change did not resonate with Mozambican stakeholders. The authors pointed out that, while country actors took the adaptation agenda seriously (at least to some extent), everyday practice which was incorporated into bureaucratic politicking was still shaped by social manipulation through competing claims on resources [37]. Research on climate risk has paid particular attention to cities in coastal areas, both because of their exposure to sea level rise, flooding and cyclones and because they are often inhabited by vulnerable populations $[38,39]$. In Africa, it is recognized that local governments often lack the capacity to deliver basic services, which makes it difficult to improve processes of planning and governance [40]. Successful climate change action depends heavily on the ability of key actors to form alliances capable of linking knowledge and institutional support to enable such action [40]. Thus, participatory urban planning is a means both to empower citizens to play a part in defining rights to an urban future and to provide access to otherwise absent services.

\section{Conclusion}

This mini-review aims to contribute to the discussion on whether climate change has contributed, and is today contributing, to food insecurity and negative health outcomes in Mozambique. The above discussion clearly shows that the answer is yes: climate change has an impact on the country's current food insecurity and in some instances it is exacerbating already existing malnutrition, stunting and diseases such as diarrhoea, malaria and cholera. However, more research is needed using empirical data that will shed light on the potential pathways and mechanisms of the relationship between climate change, food insecurity and health outcomes in the country. 
Furthermore, Mozambique needs to implement all the adaptation and mitigation strategies, which have already been approved in the national plan to ensure that climate change does not worsen the food insecurity that is currently ravaging the country. Surveillance of the impact of climate change on the most disadvantaged groups will be critical to ensure that they will not be disproportionally affected by the consequences of climate change and including health.

\section{References}

1. Thompson HE, Berrang-Ford L, Ford JD. Climate Change and Food Security in Sub-Saharan Africa: a Systematic Literature Review. Sustainability. 2010 2: $2719-2733$.

2. Ericksen $P$, Thornton $P$, Notenbaert $A$, Cramer $L$, Jones $P$, Herrero $M$. Mapping hotspots of climate change and food insecurity in the global tropics. CCAFS Report no. 5. CGIAR Research Program on Climate Change, Agriculture and Food Security (CCAFS). Copenhagen, Denmark. 2011.

3. Rouwoldt G. Food insecurity and climate change. AJPH. 2013; 103; e1.

4. Campbel BM, Vermeulen SJ, Aggarwal PK, Corner-Dolloff C, Girvetz E, Loboguerrero AM, et al. Reducing risks to food security from climate change. Global Food Security. 2016; 11: 34-43.

5. Zewdie A. Impacts of Climate Change on Food Security: A Literature Review in Sub Saharan Africa. Zewdie, J Earth Sci Clim Change. 2014; 5.

6. Tito R, Vasconcelos HL, Feeley KJ. Global climate change increases risk of crop yield losses and food insecurity in the tropical Andes. Glob Chang Biology. 2017; 1-11.

7. Wheeler T, von Braun J. Climate Change Impacts on Global Food Security. Science. 2013; 341: 508-513.

8. Gentle P, Thwaites R, Race D, Alexander K. Differential impacts of climate change on communities in the middle hills region of Nepal. Nat Hazards. 2014; 74: 815-836

9. Thomas K, Hardy RD, Lazrus H, Mendez M, Roberts JT, Rockman M, et al. Explaining differential vulnerability to climate change: A Social Science Review. WIRES climate change 2019; 10: e565.

10. Perch-Nielsen SL, Battig MB, Imboden D. Exploring the link between climate change and migration. Climatic Change. 2008; 91: 375-393.

11. Klepp S. Climate change and migration. Policy, Politics and Governments, Future Climate Change Scenarios. 2017.

12. Kaczan DJ, Orgill-Meyer J. The impact of climate change on migration: a synthesis of recent empirical insights. Climatic Change. 2020; 158: 281-300.

13. Cohen MJ, Tirado MC, Aberman N-L, Thompson B. Impact of Climate Change and Bioenergy on Nutrition. Rome: International Food Policy Research Institute. 2008

14. Noiret B. Food security in a changing climate: a plea for ambitious action and inclusive development. Development. 2016; 59: 237-244.

15. FAO, IFAD, WFP. The State of Food Insecurity in the World 2015. Meeting the international hunger targets: Taking stock of uneven progress. Rome: FAO. 2015.

16. Battisti DS, Naylor RL. Historical warnings of future food insecurity with unprecedented seasonal heat. Science. 2009; 323: 240-244.

17. Beaumier MC, Ford DJ. Food Insecurity among Inuit Women Exacerbated by Socioeconomic Stresses and Climate Change. Can J Public Health. 2010; 101: 196-201.

18. Islam MS, Wong A. Climate change and food (in) security: a critical intersection. Environments. 2017; 4: 38.

19. Ericksen PJ. Conceptualizing food systems for global environmental change research. Glob. Environ. Chang. 2008; 18: 234-245.
20. Tong S, berry HL, Ebi K, Bambrick H, Hu W, Green D, et al. Climate change, food, water and population health in China. Bull World Health Organ. 2016; 94: 759-765.

21. Friel S. Climate change, food insecurity and chronic diseases: sustainable and healthy policy opportunities for Australia. NSW Public Health Bulletin. 2010; 21: 129-133.

22. Furgal C, Seguin J. Climate change, health, and vulnerability in Canadian Northern Aboriginal communities. Environ Health Perspect. 2006; 114: 1964 1970.

23. Friel S. Food insecurity, social and health inequalities. Epidemiology. 2009; 20: S245-S246.

24. Irish Aid. Mozambique climate action report for 2016. Maputo: IA. 2017; 1-24.

25. Fridaus RBR, Gunaratne MS, Rahmat SR, Kamsi NS. Does climate change only affect food availability? What else maters? Cogent Food \& Agriculture 2019; 5: 1707607.

26. Gregory PJ, Ingram JSI, Brklacich M. Climate change and food security Philos Trans R Soc Lond Biol Sci. 2005; 360: 2139-2148.

27. Sidat MM, Vergara A. Mudancas climaticas e saude publica: uma reflexao com enfoque para Mocambique. Climate change and public health: a poin view focused on Mozambique. Rev. Cientifica. UEM: Ciencias Biomedicas e Saude Publica. 2012; 1: 39-52.

28. Macassa G, Ghilaghaber G, Charsmar H, Walander A, Sundin O, Soares J. Geographic differentials in mortality of children in Mozambique: their implications for achievement of millennium development goal 4. Journal of Health Population and Nutrition. 2012; 30: 331-345.

29. Ribeiro N, Chauque A. Gender and climate change: Mozambique case study. Food, Agriculture and Nature Resources Policy Analysis Network. 2010

30. Artur L, Hilhorst D. Everyday realities of climate change adaptation in Mozambique. Global Environmental Change. 2012; 22: 529-536.

31. SETSAN 2014 SETSAN. Relatorio de estudo base de segurança alimentar e nutricional em 2013. Maputo: Ministério da Agricultura e Segurança Alimentar. 2014

32. Abbas M. Seguranca alimentar e territorio em Mocambique: discursos politicos e practicas. Maputo: Observatorio do meio rural (CORE). Revista NERA. 2017; 38: 106-131.

33. USAID. Mudancas climaticas e vulnerabilidade de saude. Impactos na doenca diarreica e na Malaria. USAID. 2017; 1-17.

34. UNICEF. The state of the world's children 2019: Children, food and nutrition: Growing well in a changing world. New York: UNICEF. 2017; 1-258.

35. CARE 2019. https://reliefweb.int/report/mozambique/climate-change-leaves16-million-mozambique-need-urgent-assistance (Accessed 05/11/2020)

36. National Climate Change Adaptation and Mitigation Strategy. Maputo Mozambique: $39^{\text {th }}$ session of the Council of Ministers, Maputo. 2012

37. Nicholls RJ, Cazenave A. Sea-level rise and its impact on coastal zones Science. 2010; 328: 1517-1520.

38. Broto VC, Boyd E, Ensor J. Participatory urban planning for climate change adaptation in coastal cities: Lessons from a pilot experience in Maputo Mozambique. Current Opinion in Environmental Sustainability 2015; 13: 1118.

39. Parnell S, Pieterse E, Watson V. Planning for cities in the global South: an African research agenda for sustainable human settlements. Progress in Planning. 2009; 72

40. Leck H, Simon D. Fostering multiscale collaboration and co-operation for effective governance of climate change adaptation. Urban Studies. 2013; 50 $1221-1238$. 